\title{
Aromaticity of anthranil and its isomers, 1,2-benzisoxazole and benzoxazole
}

\author{
Carmen Domene, ${ }^{\mathrm{a}}$ Leonardus W. Jenneskens ${ }^{\mathrm{b}, *}$ and Patrick W. Fowler ${ }^{\mathrm{c}}$ \\ ${ }^{a}$ Physical and Theoretical Chemistry Laboratory, Oxford University, South Parks Road, Oxford OX1 3QZ, UK \\ ${ }^{\mathrm{b}}$ Debye Institute, Organic Chemistry and Catalysis, Utrecht University, Padualaan 8, $3584 \mathrm{CH}$ Utrecht, The Netherlands \\ ${ }^{\mathrm{c}}$ Department of Chemistry, University of Exeter, Stocker Road, Exeter EX4 4QD, UK
}

Received 14 February 2005; revised 28 March 2005; accepted 5 April 2005

Available online 19 April 2005

\begin{abstract}
Direct computation of the $\pi$-current density, that is, the 'ring current', of anthranil (1) and its isomers 1,2-benzisoxazole (2) and benzoxazole (3) reveals different patterns of current flow: isomers $\mathbf{2}$ and $\mathbf{3}$ sustain strong benzene-like currents in the sixmembered and bifurcated flow in the five-membered ring, whereas, in keeping with its lower thermodynamic stability, $\mathbf{1}$ has only a perimeter circulation without separate monocycle currents. Although the ring current criterion does not offer a sharp distinction between $\mathbf{2}$ and 3, their difference in thermodynamic stability is identical to that between isoxazole (4) and oxazole (5) suggesting an aromaticity order $\mathbf{1}<\mathbf{2} \approx \mathbf{3}$.
\end{abstract}

(C) 2005 Elsevier Ltd. All rights reserved.

The extent to which energetic, reactivity and magnetic criteria of aromaticity are descriptions of a single, unifying property of molecules remains a matter of debate. ${ }^{1}$ Anthranil (1) and its isomers 1,2-benzisoxazole (2) and benzoxazole (3) offer a series of bicyclic molecules with different arrangements of two strongly electronegative heteroatoms (Scheme 1). A combination of experimental thermochemical data, calculated energies and magnetic (NICS: nucleus-independent chemical shifts ${ }^{2}$ ) indices is available for this set. ${ }^{3}$ Anthranil (1) is found to be significantly less stable $\left(\Delta H_{\mathrm{f}}^{0} 180.8 \mathrm{~kJ} \mathrm{~mol}^{-1}\right)$ than its isomers $\mathbf{2}\left(\Delta H_{\mathrm{f}}^{0} 138.9 \mathrm{~kJ} \mathrm{~mol}^{-1}\right)$ and $\mathbf{3}\left(\Delta H_{\mathrm{f}}^{0} 44.8 \mathrm{~kJ} \mathrm{~mol}^{-1}\right){ }^{3}$ However, inspection of the calculated NICS values (Scheme 1) suggested a different view. "... It would appear that the aromaticity of these three species [is] very nearly the same ...." ${ }^{3}$ In fact, the quoted magnetic calculations reveal two different patterns for the three isomers: within a roughly constant total over the two rings, 1 has a large negative NICS associated with the pentagonal ring, whereas $\mathbf{2}$ and $\mathbf{3}$ have somewhat larger negative NICS associated with the hexagonal carbocyclic ring. In the usual interpretation, this would indicate differential local aromaticities. Here we show that these data are interpreted by consideration of the basic

\footnotetext{
Keywords: Aromaticity; Ring currents; Ab initio calculations.

* Corresponding author. Tel.: +31 30253 3128; fax: +31 30253

4533; e-mail: 1.w.jenneskens@chem.uu.nl
}

property underlying NICS: the current density induced by a perpendicular magnetic field, that is, the 'ring current', which gives an insight into the essential difference between anthranil (1) on the one hand and its two isomers $\mathbf{2}$ and $\mathbf{3}$ on the other.

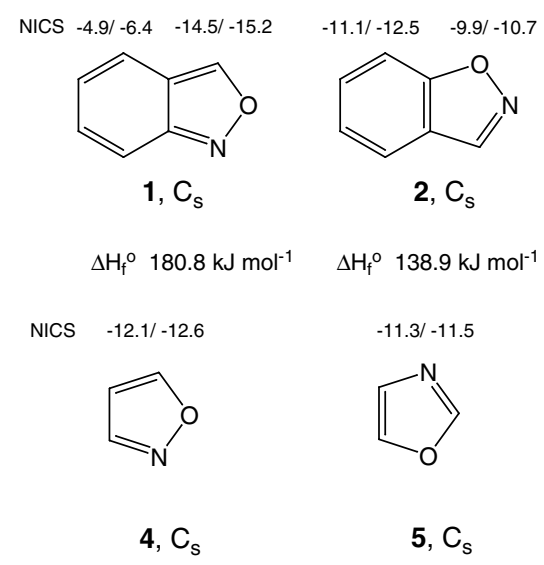

$1, C_{s}$

2, $\mathrm{C}_{\mathrm{s}}$

$\Delta \mathrm{H}_{\mathrm{f}}^{\mathrm{0}} 180.8 \mathrm{~kJ} \mathrm{~mol}^{-1}$

$\Delta \mathrm{H}_{\mathrm{f}}^{\circ} 138.9 \mathrm{~kJ} \mathrm{~mol}^{-1}$

NICS

$$
-12.1 /-12.6
$$

$4, C_{s}$

$5, \mathrm{C}_{\mathrm{s}}$

$\Delta \mathrm{H}_{\mathrm{f}}^{0} 44.8 \mathrm{~kJ} \mathrm{~mol}^{-1}$<smiles>c1ccc2ocnc2c1</smiles>

$3, \mathrm{C}_{\mathrm{s}}$

$\Delta \mathrm{H}_{\mathrm{f}}^{0} 78.6 \mathrm{~kJ} \mathrm{~mol}^{-1}$

$\Delta \mathrm{H}_{\mathrm{f}}{ }^{0}-15.5 \mathrm{~kJ} \mathrm{~mol}^{-1}$

Scheme 1. Compounds under investigation $\left(\mathrm{NICS}^{2}\right.$ values in ppm for the five- and six-membered rings at the ring centre $(0.0 \AA)$ and $0.5 \AA$ above, and experimental $\Delta H_{\mathrm{f}}^{0}$ values taken from Ref. 3). All except 6 have a single plane of symmetry and hence belong to the $C_{s}$ point group; for $\mathbf{6}, C_{s}$ symmetry is imposed as a constraint in order to improve clarity. 

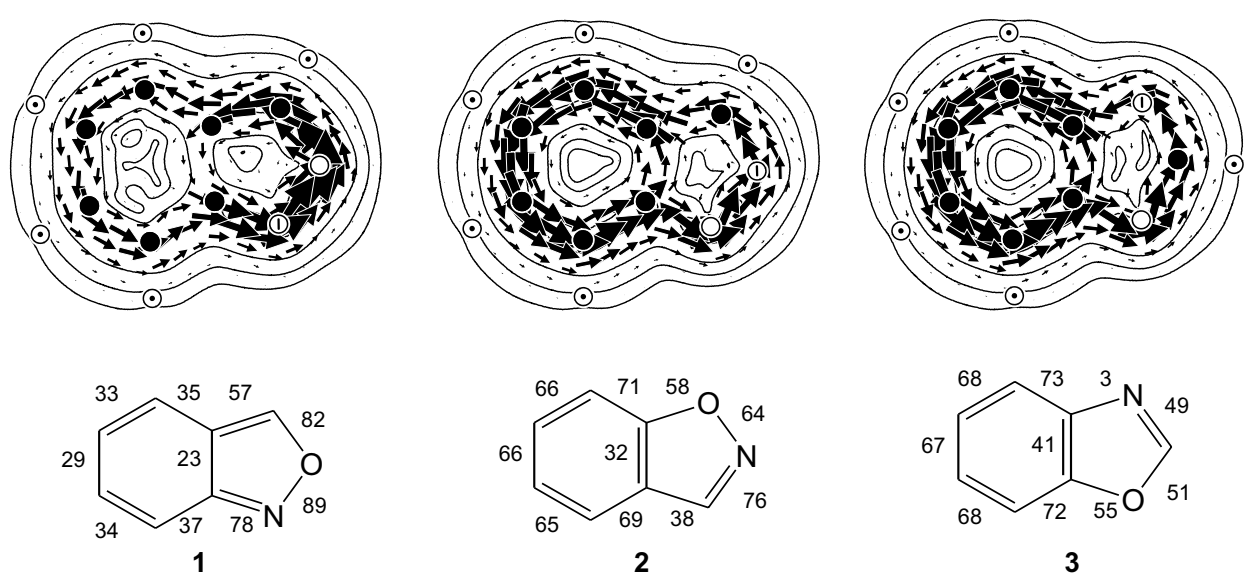

Figure 1. CTOCD-DZ/6-31G**//RHF/6-31G** $\pi$-current density maps of $\mathbf{1}, \mathbf{2}$ and $\mathbf{3}^{7}$ The inset pictures summarize the maps in terms of current densities over bond-midpoints in milli-atomic units, where the equivalent value for benzene would be $79 .^{5}$

Figure 1 shows $\pi$-current density maps for $\mathbf{1}, \mathbf{2}$ and $\mathbf{3}$ computed within the established methodology (optimization of geometry at the ab initio RHF/6-31G** level of theory ${ }^{4}$ followed by ipsocentric calculation of current density induced by a perpendicular magnetic field using the ab initio CTOCD-DZ/6-31G** method $^{5}$ ). Standard plotting conventions for the current density maps are used (diatropic current anticlockwise (aromatic character) and paratropic current clockwise (antiaromatic character)). ${ }^{6,7}$ Advantages of this approach include computational economy, accuracy and a ready visualization of the results in terms of physically non-redundant orbital contributions. ${ }^{5,7,8}$ The currents shown in Figure 1 are those arising from the $\pi$ electrons. It is apparent that all three systems sustain a diatropic perimeter ring current, and hence all qualify as 'aromatic' on the magnetic criterion. The induced currents are non-negligible. As the schematic summary in Figure 1 (bottom) shows, the average current density over the bonds of the six-membered ring (calculated from the current density per unit external field at a height of $1 \mathrm{bohr}$ over the geometric midpoint of each bond) is $40 \%$ (1), 78\% (2) and $82 \%$ (3) of the maximum value for benzene calculated in the same approach. ${ }^{4,7}$ Closer inspection reveals an essential difference between the $\pi$-current density map for $\mathbf{1}$ and those for $\mathbf{2}$ and $\mathbf{3}$. In anthranil (1) the current flows in a single loop with only little 'leakage' across the ring-fusion bond. In contrast, both 1,2-benzisoxazole (2) and benzoxazole (3) exhibit a bifurcated flow in which significant current returns across the ring-fusion bond to complete a benzene-like circulation in the six-membered ring. Thus, $\mathbf{1}$ has a naphthalene-like ${ }^{5}$ pattern of ring current, whereas 2 and 3 appear as annelated benzenes, in which the five-membered ring does not of itself sustain a complete diatropic ring current. Free isoxazole (4) and oxazole (5) themselves show typical diatropic $\pi$ ring currents (Fig. 2).

The ipsocentric method makes a direct link between ring current and frontier-orbital symmetries and nodal patterns. ${ }^{5-8}$ A simple symmetry argument shows that the diatropic current of an aromatic planar $4 n+2$ monocycle
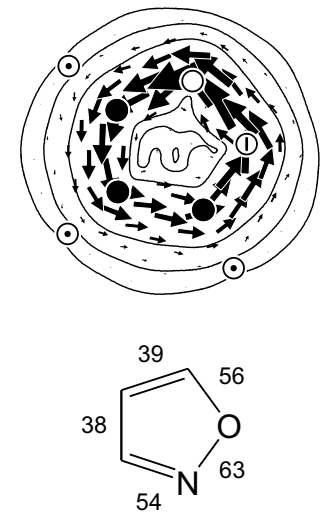

4
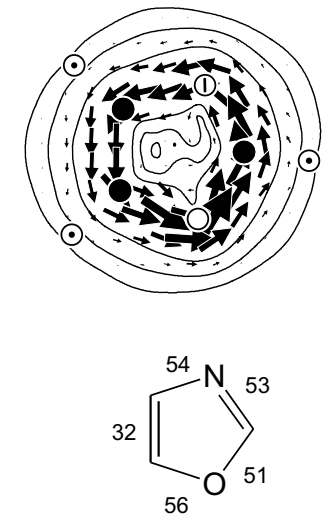

5
Figure 2. CTOCD-DZ/6-31G**//RHF/6-31G** $\pi$-current density maps of $\mathbf{4}$ and 5. ${ }^{7}$ The inset pictures summarize the maps in terms of current densities over bond-midpoints in milli-atomic units, where the equivalent value for benzene would be 79.5

arises from the mobility of the four HOMO electrons. ${ }^{5,8}$ An analysis of orbital contributions to the maps of Figure 1 shows that all three cases obey this counting rule: the total $\pi$-current is reproduced by the sum of contributions from the four electrons in HOMO and HOMO-1 (now split in energy by the low molecular symmetry). We note that $\mathbf{1}$ and $\mathbf{2}$ are formally related to the ninemembered $10 \pi$-electron monocycle 1,2-oxazonine (6) by introduction of an appropriate cross-link (Scheme 2). ${ }^{3}$ If constrained to planarity, the $C_{s}$ oxazonine cycle, $\mathbf{6}$, is found in the present approach to sustain a diatropic current (Fig. 3). The concentration of ring current in the

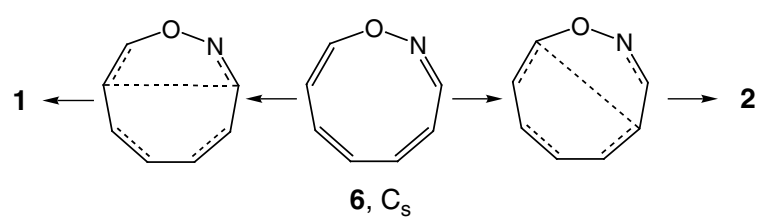

Scheme 2. Formal cross-linking relationship between planar oxazonine (6), anthranil (1) and 1,2-benzisoxazole (2). 


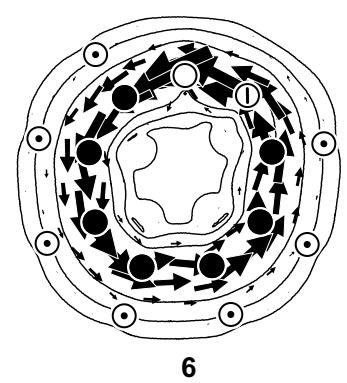

Figure 3. CTOCD-DZ/6-31G**//RHF/6-31G** $\pi$-current density map of planar $\mathbf{6}^{7}$

frontier-orbitals of $\mathbf{1}$ and $\mathbf{2}$ stems from this formal ancestry in originally degenerate orbitals that are cut by two nodal planes lying perpendicular to the plane of the nuclei. As Figure 4 shows, the nodal planes indeed adopt naphthalene-like patterns in $\mathbf{1}$, but in $\mathbf{2}$ and $\mathbf{3}$ they retain a recognizable benzene-like pattern with the six-membered sub-unit bisected by orthogonal single nodal planes in the HOMO and HOMO-1.

The ring current maps also suggest an interpretation of the trends in NICS values. The coherent benzenoid current in the six-membered ring in $\mathbf{2}$ and $\mathbf{3}$ would be expected to produce a large out-of-plane component of nucleus-independent shielding which, on averaging and sign reversal, ${ }^{2,6}$ contributes to the calculated negative NICS. In 1, the small current in the ring-fusion bond completes a diatropic circuit in the five-membered ring. The bifurcated flow in the six-membered ring of $\mathbf{1}$ and in the five-membered rings of $\mathbf{2}$ and $\mathbf{3}$ lead to internal cancellation in the out-of-plane component of nuclear shielding.

The structure of the NICS values listed in Scheme 1 is thus rationalized with the help of the more detailed information available from direct inspection of the currents. The maps also show that $\mathbf{2}$ and $\mathbf{3}$ have stronger benzene-ring currents than 1, in keeping with anthranil's lower thermodynamic stability, although the magnetic criteria offer no clear distinction between the isomers 1,2-benzisoxazole (2) and benzoxazole (3). Indeed, if we note that the difference in $\Delta H_{\mathrm{f}}^{0}$ between $\mathbf{2}$ and $\mathbf{3}$ $\left(\Delta \Delta H_{\mathrm{f}}^{0} \quad 94.1 \mathrm{~kJ} \mathrm{~mol}^{-13}\right.$ with $\mathrm{RHF} / 6-31 \mathrm{G}^{* *} \quad \Delta E_{\mathrm{tot}}$ $\left.132.00 \mathrm{~kJ} \mathrm{~mol}^{-1}(0.050277 \text { hartree })^{4}\right)$ is identical to that between isoxazole $\left(4, \Delta H_{\mathrm{f}}^{0} 78.6 \mathrm{~kJ} \mathrm{~mol}^{-13}\right)$ and oxazole (5, $\Delta H_{\mathrm{f}}^{0} \quad-15.5 \mathrm{~kJ} \mathrm{~mol}^{-13} \quad \mathrm{RHF} / 6-31 \mathrm{G}^{* *} \quad \Delta E_{\text {tot }}$ $\left.116.98 \mathrm{~kJ} \mathrm{~mol}^{-1}(0.044556 \text { hartree })^{4}\right)$, the conclusion of similar aromaticity of $\mathbf{2}$ and $\mathbf{3}$ is reasonable on both energetic and magnetic criteria.

\section{Acknowledgements}

P.W.F. thanks the EU for financial support from the Framework V programme (RTN Contract HPRN-CT2002-00136 'WONDERFULL') and the Royal Society/ Wolfson Scheme for a Research Merit Award. C.D. thanks the Royal Society for a University Research Fellowship.

\section{References and notes}

1. Cyran̆ski, M. K.; Krygowski, T. M.; Katritsky, A. R.; Schleyer, P. von R. J. Org. Chem. 2002, 67, 1333-1338.

2. Schleyer, P. von R.; Maerker, C.; Dransfeld, A.; Jiao, H.; van Eikema Hommes, N. J. R. J. Am. Chem. Soc. 1996, 118, 6317-6318.

3. Matos, M. A. R.; Miranda, M. S.; Morias, V. M. F.; Liebman, J. L. Eur J. Org. Chem. 2004, 3340-3345.

4. RHF/6-31G** $E_{\text {tot }}$ values: $1-397.231996,2-397.255196$, $3-397.305473,4-244.594185,5-244.638741$ and $\mathbf{6}$ (planar geometry), -398.272222 hartree.

5. Steiner, E.; Fowler, P. W. J Phys Chem A 2001, 105, 95539562.

6. Soncini, A.; Havenith, R. W. A.; Fowler, P. W.; Jenneskens, L. W.; Steiner, E. J. Org. Chem. 2002, 67, 4753-4758.

7. The maps show the $\pi$-current density induced by a perpendicular external magnetic field and plotted in a plane 1 bohr above that of the nuclei. Arrows indicate the relative strength of the in-plane projection of current, and contours show the magnitude of the full three-dimensional current, in both cases taking only $\pi$-electron contributions into
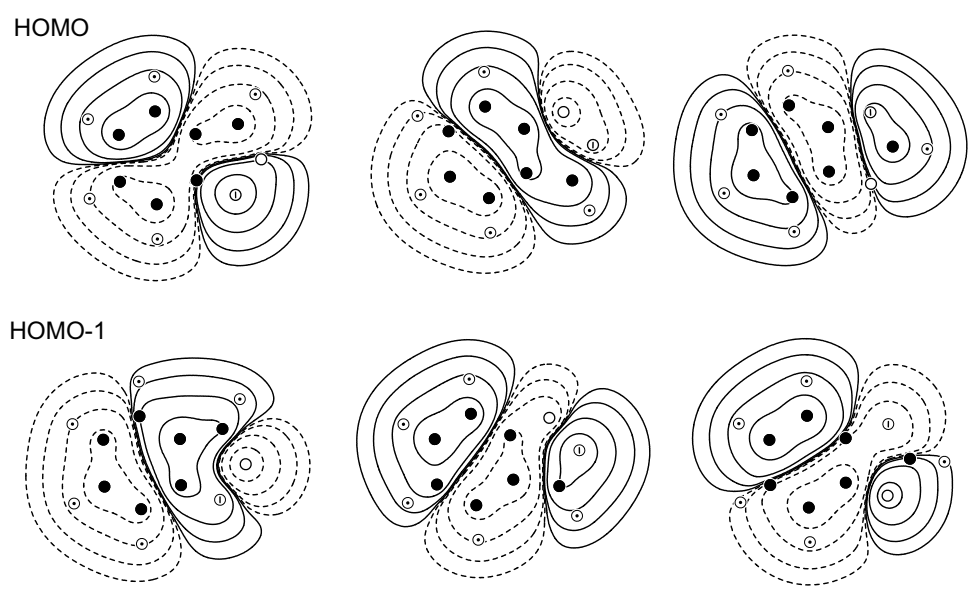

1 
account. Projections of nuclear positions are indicated by filled, barred, empty and dotted circles for carbon, nitrogen, oxygen and hydrogen, respectively. Inset schemes beneath a map show the current density in the plotting plane over each bond-midpoint, expressed in milli-atomic units of current density per unit inducing field. In these units, the maximum $\pi$-current density in the $1 \mathrm{bohr}$ plane is 79 over each bond-midpoint for benzene itself. ${ }^{5}$
The ability to sustain an anticlockwise diatropic current is taken as the signature of aromaticity in a cyclic molecule; in a similar way, a clockwise paratropic ring current corresponds to antiaromaticity. See for a recent review: Fowler, P. W.; Steiner, E.; Havenith, R. W. A.; Jenneskens, L. W. Magn. Reson. Chem. 2004, 42, S68-S78.

8. Steiner, E.; Fowler, P. W. Chem. Commun. 2001, 2220 2221. 